\title{
Anomalous behavior of the thermal conductivity of a molecular crystals composed of flexible molecules at high temperatures
}

Yuliia V. Horbatenko ${ }^{1}$, Olesia O. Romantsova ${ }^{1}$, Oksana A. Korolyuk ${ }^{1}$, Andrzej Jeżowski², Daria Szewczyk ${ }^{2}$, Joseph Ll. Tamarit ${ }^{3}$, Alexander I. Krivchikov ${ }^{1}$

${ }^{1}$ B.Verkin Institute for Low Temperature Physics and Engineering of the NAS of Ukraine, 47 Nauky Ave., Kharkiv, 61103, Ukraine

${ }^{2}$ Institute of Low Temperature and Structure Research, PAS, 2 Okólna Str., 50-422 Wrocław, Poland

${ }^{3}$ Grup de Caracterització de Materials, Departament de EEBE and Barcelona Research Center in Multiscale Science and Engineering, Eduard Maristany, 10-14, 08019 Barcelona, Catalonia, Spain

E-mail:krivchikov@ilt.kharkov.ua

The thermal conductivity $\kappa(T)$ of molecular polycrystals have been investigated.

The materials studied were para-chloronitrobenzene, pentachloronitrobenzene, and freons.

The $\kappa(T)$ increases abnormally with temperature in the high-temperature region.

The anomaly is connected to the thermal activation mechanism of heat transfer.

Abstract
The temperature dependence of thermal conductivity $\kappa(T)$ of selected molecular polycrystals consisting of flexible molecules have been investigated between $20-260 \mathrm{~K}$. The materials were para-chloronitrobenzene, pentachloronitrobenzene, freon F-112 and freon-113. It is found that the $\kappa(T)$ of these crystals increases with temperature in the interval where the processes of phonon - phonon scattering are dominant. The increase is observed both in the orientationally-ordered and orientationally-disordered phases and is typical of the thermally activated heat transfer by low-energy localized molecular excitations [M. A. Strzhemechny et al., Chem. Phys. Lett. 647 (2016) 55]. In a wide interval of temperatures, irrespective the glass 
transition temperature, the $\kappa(T)$ can be described by a sum of three components: $\kappa(T)=A / T+B$ $+\kappa_{\mathrm{TA}}(T)$. The term $(A / T)$ accounts for phonon-phonon scattering processes, the term $(B)$ is temperature - independent and accounts for the diffuse phonon scattering. The third contribution is described by the Arrhenius equation: $\kappa_{\mathrm{TA}}(T)=\kappa_{0} \exp \left(-E / k_{B} T\right)$, where $E$ is the activation energy and $\kappa_{0}$ is the pre-exponential factor characterizing the intensity of the heat transfer process. A comparative analysis of anomalous thermal conductivities of some other molecular crystals was carried out. It is found that $\kappa_{0}$ depends linearly on the activation energy. Similar correlation is found for a series of quasicrystals.

PACS: 66.70.-f Non-electron thermal conductivity and propagation of a thermal pulse in solids; thermal waves;

63.20.kk Interaction of phonons with other quasiparticles.

Keywords: thermal conductivity, polymorphism, phonons, diffusive modes, hybridization, locons. 


\section{Introduction}

The thermal conductivity $\kappa(T)$ in fully ordered phases of atomic noble gas cryocrystals and simple molecular cryocrystals is determined by phonon-phonon scattering processes [1], and can be approximated by the universal dependence $\kappa(T) \sim T^{-1}$ (the Eucken law) in a wide temperature interval, in the high-temperature region, where the influence of other crystal defects (dislocations, point defects, etc.) can be neglected. The extensive experimental evidence currently available on isochoric and isobaric thermal conductivities of molecular crystals shows that the dependence $\kappa(T)$ is also influenced by crystal lattice anharmonicities [2] and intensive hybridization (coupling) of acoustic phonons and low-frequency optical excitations (e.g., see [313]). It has been found that for many molecular crystals the high-temperature thermal conductivity can be approximated as a sum of two terms $\kappa(T)=A / T+B$, where $A / T$ refers to the effect of propagating phonons (Eucken law) and $B=$ const refers to an additional temperatureindependent contribution of localized or diffusive short-wavelength vibrational modes.

On the contrary, in canonical structural glasses, whose molecules are devoid of positional and orientational order, the thermal conductivity is much lower than the crystalline counterparts and its temperature dependence behaves quite differently: in the low temperature region $(<2 \mathrm{~K})$ $\kappa(T) \sim T^{2}$, then, on increasing temperature the thermal conductivity flattens first, grows monotonically afterwards and finally forms another "plateau" $[9,14,15]$.

In more complex structures (see experimental and modeling data [16]) the heat exchange processes are more intricate involving energy hopping between non-propagating localized vibrational modes (predicted in [17]). In fact, anharmonic coupling between localized modes and between localized and delocalized modes controls the heat conduction, the effect being enhanced with temperature.

Within the world of molecular crystals there is a broad group of substances whose constituent molecules possess a set of internal low-energy local modes. These localized states influence the heat capacity, and some of them are involved in heat transfer processes as well. Under a temperature gradient, the flow of such energy states are highly temperature dependent and the dependence increases with increasing the number of excited states migrating between the neighboring molecules. The new type of heat transfer was detected in a single crystal of parabromobenzophenone (4-BrBP $\left.\mathrm{C}_{13} \mathrm{H}_{9} \mathrm{BrO}\right)$ [11]. Such a contribution to the total thermal conductivity can be described by the Arrhenius equation: $\kappa_{\mathrm{TA}}(T)=\kappa_{0} \exp \left(-E / k_{B} T\right)$, where $E$ is the activation energy and $\kappa_{0}$ is the pre - exponential factor characterizing the intensity of the thermally activated heat transfer. The thermally activated heat transfer was also observed in a 
monoclinic modification of this substance [12], benzophenone (BP, $\left.\left(\mathrm{C}_{6} \mathrm{H}_{5}\right)_{2} \mathrm{CO}\right)$ [13] and 2-adamantanone $\left(\mathrm{C}_{10} \mathrm{H}_{14} \mathrm{O}\right)[18]$.

The present work discusses the thermal conductivity of some selected substances consisting of flexible molecules whose thermal conductivities behave anomalously in a high temperature region, more specifically, above the maximum of $\kappa(T)$. The experimental selected compounds were two apparently rigid molecules, para-chloronitrobenzene $\mathrm{C}_{6} \mathrm{H}_{4} \mathrm{ClNO}_{2}$ (hereinafter p-CNB), pentachloronitrobenzene $\mathrm{C}_{6} \mathrm{Cl}_{5} \mathrm{NO}_{2}$ (hereinafter PCNB), and two clearly flexible molecules with conformational disorder, as the halogen-ethane derivatives $\mathrm{CFCl}_{2}-\mathrm{CFCl}_{2}$ (hereinafter freon $\mathrm{F}-112$ ) and $\mathrm{CCl}_{2} \mathrm{~F}-\mathrm{CClF}_{2}$ (hereinafter freon $\mathrm{F}-113$ ), both of them displaying different conformational isomers. The results obtained were analyzed and compared with data for other crystals exhibiting similar anomalies at high temperatures. Our purpose here is to reveal similarities and differences in the anomalous behavior of $\kappa(T)$ of the aforementioned molecular crystals in the "high-temperature" region and to elucidate the physical factors responsible for such a behavior.

\section{Materials}

The substance p-CNB is orientationally disordered in the solid state, melting point is $T_{\mathrm{m}}=355 \mathrm{~K}$. The cyclic molecules occupy distinct positions in the crystal, but they can have two possible orientations to generate a centrosymmetrical crystal $\left(P 2_{1} / c\right)$. Besides, there is a complementary type of disorder in p-CNB induced by reorientation ("tilting") of the nitro-group relative to the aromatic ring. According to X-ray diffraction data [19], the p-CNB molecule exhibits a two-fold orientational disorder of the $\mathrm{NO}_{2} / \mathrm{Cl}$ substituents, the center of the molecule being a center of inversion. It was found $[20,21]$ that at $T \approx 282.6 \mathrm{~K} \mathrm{p}$-CNB undergoes a firstorder phase transition. According to NQR (nuclear quadrupole resonance) and DTA (differential thermal analysis) data [20], above $T \approx 282.6 \mathrm{~K}$ the crystal is a dynamically disordered monoclinic structure, space group $P 2_{1} / c(Z=2)$, (phase I) [21], where $Z$ is the number of molecules in the unit cell. When cooled to low temperature, supercooled state of phase I transforms into an orientational glass $\left(T_{\mathrm{g}}=245 \mathrm{~K}[22,23]\right)$, in which the molecular reorientation is kinetically frozen in. Then, on annealing the supercooled state of phase I transforms at $T \approx 250$ $\mathrm{K}$ into the stable phase II as a result of an irreversible first-order phase transition [20]. The investigation by means of X-ray diffraction study of polycrystalline $\mathrm{p}$-chloronitrobenzene phase II revealed a monoclinic ordered structure of space group $P 2_{1}(Z=2)$ [21]. An schematic representation of the ordered and disordered molecular arrangements is shown in Fig. 3 of reference [21]. The material shows quite intensive thermal motion with strong constrains 
concerning the motion of the oxygen atoms relative to each other, which causes asymmetric libration of the nitro-group in the whole temperature interval [19].

PCNB (pentachloronitrobenzene, $\mathrm{C}_{6} \mathrm{Cl}_{5} \mathrm{NO}_{2}$ ) is another example of hexasubstituted benzene molecule displaying well-defined disorder in the solid state involving exclusively orientational disorder while the molecular centers of mass form an ordered lattice $\left(T_{\mathrm{m}}=415 \mathrm{~K}\right.$, $T_{\mathrm{g}}=191 \mathrm{~K}$ [24]). DSC (differential scanning calorimeter) and TSDC (thermally stimulated depolarization currents) investigations [25] showed that the reorientational motion of the molecule proceeds in the plane of the aromatic ring - about the axis perpendicular to the ring. PCNB has a layered rhombohedral structure, space group $R \overline{3}(Z=3)$ [26]. It may be considered as a strongly anisotropic crystal with low-dimensional orientational disorder [27]. Monte Carlo computer simulations [26] show that each site of the rhombohedral lattice $R \overline{3}$ in PCNB contains a molecule with six different equally probable orientations, which ensures the existence of a six-fold like symmetry around an axis perpendicular to the benzene ring. Besides, in the interval from room temperature to $5 \mathrm{~K}$ the dynamic disorder does not change essentially, except for a possible attenuation of the nitro-group libration (out-of-plane librations). It is found that the potential energy profile has six equal minima corresponding to the six-fold rotation of the molecules. Recent dielectric studies as a function of pressure and temperature probe that the orientational dynamics of PCNB is highly anisotropic and the system exhibits a double primary relaxation feature associated with the in-plane and out-of-plane molecular dipole reorientations [28].

Freons F-112 $\left(\mathrm{CFCl}_{2}-\mathrm{CFCl}_{2}\right)$ and F-113 $\left(\mathrm{CCl}_{2} \mathrm{~F}-\mathrm{CClF}_{2}\right)$ are materials displaying orientationally disordered phases (plastic phases) below the melting temperature [29]. In addition, both materials display internal molecular degrees of freedom, in particular rotation about the chemical $\mathrm{C}-\mathrm{C}$ bond, which allows the existence of several conformers. The molecules of F-112 and F-113 have a dumb-bell shape and can exist in gauche or trans conformational states (F-112) [30] or in the states $C_{1}$ and $C_{\mathrm{S}}(\mathrm{F}-113)$. Freons F-112 and F-113 are mixtures of conformers, the proportion of which being temperature dependent.

F-112 displays a complex thermal behavior as revealed by different thermal anomalies. On cooling from the liquid state, a body-centered cubic phase appears at ca. $300 \mathrm{~K}$. Such a phase displays, as the liquid state, a mixture of gauche and trans conformers [30]. On further cooling, the conformational degree of freedom is arrested at ca. $130 \mathrm{~K}$, in such a way that proportion of conformers is stuck, but molecules can still reorient as a whole within the plastic phase. At lower temperature, the orientational disorder of the plastic phase is frozen at $T_{\mathrm{g}}=90 \mathrm{~K}$ [29] and thus an 
orientational glass appears. Finally, at $60 \mathrm{~K}$ a thermal anomaly was described and attributed to a secondary relaxation.

As far as the Freon F-113 is concerned, the heat capacity measurements in the interval $6 \mathrm{~K}-300 \mathrm{~K}$ revealed also the existence of ordered and orientationally disordered phases [31, 32]. The phase with dynamic orientational disorder forms below the melting point, $T_{\mathrm{m}}=238 \mathrm{~K}$. This body-centered cubic phase can be easily supercooled to form an orientational glass at $T_{\mathrm{g}} \approx 72 \mathrm{~K}$ [30]. Above $120 \mathrm{~K}$ the molecules can undergo large-angle fluctuations as well as $C_{1}-C_{\mathrm{S}}$ or $C_{\mathrm{S}}$ $C_{1}$ conformational transitions; below $120 \mathrm{~K}$ the molecular motion reduces to reorientation and small-angle torsional fluctuations [33]. Both F-113 and F-112 are known to be very fragile systems, i.e. systems in which the reorientational relaxation time changes strongly with temperature when approaching the glass transition temperature $[34,35]$.

\section{Experimental technique}

The starting materials p-CNB and PCNB were powders purchased from Sigma Aldrich with of chemical purity over 99\%. The polycrystalline p-CNB and PCNB samples for measurements of thermal conductivity were prepared by mechanical compression $\left(1500 \mathrm{~kg} / \mathrm{cm}^{2}\right)$ at room temperature, so both of them in the orientationally disordered phase. Geometrically, the samples were cylinders of $5 \mathrm{~mm}$ in diameter and $12 \mathrm{~mm}$ in length. The thermal conductivities of p-CNB and PCNB were measured in the setup using the method of a steady-state linear heat flow $[36,37]$. Initially, the thermal conductivity was measured in the orientationally disordered phase $(T=30 \mathrm{~K}-220 \mathrm{~K})$. As for the orientationally ordered phase of $\mathrm{p}-\mathrm{CNB}$, it was obtained in the setup by a non-equilibrium solid - state first order phase transition in the sample through annealing 72 hours at $T \approx 250 \mathrm{~K}$ [20]. The phase transformation was controlled by measuring the thermal conductivity changes.

The measurements on freons were made using the following materials: 1,1,2,2tetrachloro-1,2,-difluoroethane $\left(\mathrm{CCl}_{2} \mathrm{~F}-\mathrm{CCl}_{2} \mathrm{~F}, \mathrm{~F}-112\right)$ purchased from $\mathrm{ABCR}$ GmbH\& Co. KG with purity better than $99 \%$ and 1,2,2-trichloro-1,1,2- trifluoroethane $\left(\mathrm{CCl}_{2} \mathrm{~F}-\mathrm{CClF}_{2}, \mathrm{~F}-113\right)$ purchased from Sigma-Aldrich with purity higher than $99.9 \%$. The thermal conductivities of F112 and F-113 were measured under equilibrium vapor pressure in the setups using the method of a steady-state linear heat flow. Two samples of Freon F-112 were measured at two different setups. The thermal conductivity of sample 1 of Freon F-112 in the temperature range $20 \mathrm{~K}-200$ $\mathrm{K}$ and the F-113 freon sample in the temperature range $14 \mathrm{~K}-123 \mathrm{~K}$ was measured at the setup $[38,39]$ in which the sample container was stainless steel tube. In this setup, a copper thermal shield is used to compensate radiation heat-losses effects during measurements of thermal conductivity. It surrounds the container with the sample. The measuring container is separated 
from the outer helium bath by a vacuum jacket. The vacuum in the jacket is maintained at a level of $10^{-5}-10^{-4} \mathrm{~Pa}$ during the measurement of thermal conductivity. However, in order to be sure of the accuracy of the experimental data at temperatures where radiation effects may be significant, the thermal conductivity of sample 2 of F-112 was measured in the temperature range $110 \mathrm{~K}-290 \mathrm{~K}$ at the setup [36, 37]. Measurements were performed under high vacuum and with four shields mounted around the sample, thus reducing the heat losses due to radiation. The experimental data of two samples of Freon F-112, obtained with two different setups perfectly match. Samples of freons F-112 and F-113 were liquids at room temperature. Polycrystalline sample 2 of F-112 was grown in a cylindrical polyethylene ampoule (I.D. $8.7 \mathrm{~mm}$ and O.D. $10.0 \mathrm{~mm}$ ). The temperature gradient was measured with thermocouple temperature sensors [36, 37]. The growth of samples and the obtaining of their different states occurred identically at two different setups. Orientational glass state was prepared by very fast cooling (above $50 \mathrm{~K} \mathrm{~min}^{-1}$ ) of the orientationally disordered crystal sample through the glass-transition region to the boiling temperature of liquid $\mathrm{N}_{2}$. The thermal conductivity of the orientational glass state of freons was measured at gradually decreasing temperature from the temperature of liquid $\mathrm{N}_{2}$ to $20 \mathrm{~K}$ (for F-112) and from the temperature of liquid $\mathrm{N}_{2}$ to $14 \mathrm{~K}$ (for F-113) and then increasing temperature up to the maximum temperature of the experiment. During the measurements of the thermal conductivity in the high-temperature region (above $100 \mathrm{~K}$ ) and at the transition from one experimental point to another, the change in the sample temperature by $10 \mathrm{~K}$ and the establishment of the steady-state regime were 5-6 hours. At temperatures on the order of $14 \mathrm{~K}$, the change in the sample temperature by $2 \mathrm{~K}$ and the establishment of the steadystate regime amounted to about 2 hours. The experimental data did not depend on the rate of heating or cooling of the sample inside the obtained phase.

The thermal conductivity of the empty polyethylene ampoule in the setup [36, 37] was measured previously in a wide temperature range. The thermal conductivity of solid sample 2 freon F-112 was obtained by separating the heat flows over the ampoule walls and the solid freon sample. The temperature gradient along the sample was typically $0.2-0.3 \mathrm{~K}$ in steady-state regime, at measuring the thermal conductivity at a specific temperature. The maximum experimental systematic error was below $15 \%$ (caused mainly by the uncertainties in the sample geometry). The error estimated from the dispersion of the experimental points did not exceed $\pm 2 \%$ [36]. In the experiments with sample 1 of F-112 and F-113, the thermal conductivity of the empty stainless steel container also was measured previously. The thermal conductivity of solid sample was obtained by separating the heat flows over the sample container and the sample [38, 39]. The random error in measuring the thermal conductivity did not exceed $3 \%$. The total 
measurement error was $\sim 10 \%$ and was mainly related to the systematic error, which was determined by measuring the geometric parameters of the container.

\section{Experimental results}

The temperature dependence of the thermal conductivity measured on p-CNB crystals in the orientationally ordered and disordered phases and on the orientationally disordered PCNB $(T=30 \mathrm{~K}-260 \mathrm{~K})$ are shown in Fig. 1 in log-log scale. Previously, the thermal conductivity of orientationally disordered PCNB was measured at lower temperatures (4 K - $110 \mathrm{~K})$ [27], which are also indicated in the figure, for comparison. It is seen that in the case of PCNB our data are in good agreement with the literature data in the temperature range $30-110 \mathrm{~K}$. The Fig. 1 also shows the glass transition temperatures $T_{\mathrm{g}}$ for $\mathrm{p}-\mathrm{CNB}$ and PCNB (vertical dotted lines). The $\kappa(T)$ of orientationally ordered p-CNB displays a bell-shaped curve, which is typical of orientationally ordered crystals below $100 \mathrm{~K}$. As the temperature increases, the thermal conductivity grows too and reaches a maximum $\left(\kappa_{\max }=3.3 \mathrm{~W} \mathrm{~m}^{-1} \mathrm{~K}^{-1}\right)$ at $T_{\max }=14 \mathrm{~K}$. Usually, in molecular crystals, this increase is due to the scattering of long-wave phonons by defects (grain boundaries, dislocations) [40]. Then it falls to a minimum $\left(\kappa_{\min } \approx 0.4 \mathrm{~W} \mathrm{~m}^{-1} \mathrm{~K}^{-1}\right)$ at $T_{\min } \approx 188 \mathrm{~K}$ and from there it continues to grow anomalously up to $\kappa \approx 0.5 \mathrm{~W} \mathrm{~m}^{-1} \mathrm{~K}^{-1}$ at the highest temperature of measurement $(\approx 260$ $\mathrm{K})$.

The thermal conductivity $\kappa(T)$ of the orientationally disordered p-CNB is much lower and than for the ordered counterpart phase, as typically found in glasses. From $30 \mathrm{~K}$ to $77 \mathrm{~K}$, the thermal conductivity grows slightly and flattens out within the temperature range between $77 \mathrm{~K}$ and $100 \mathrm{~K}$. Above $T=100 \mathrm{~K}, \kappa(T)$ increases anomalously up to $\kappa \approx 0.17 \mathrm{~W} \mathrm{~m}^{-1} \mathrm{~K}^{-1}$ at the highest temperature of measurement $\left(\approx 220 \mathrm{~K}<T_{\mathrm{g}}=245 \mathrm{~K}\right)$.

The thermal conductivity of the orientationally disordered PCNB shows a similar glasslike behavior. However, the temperature interval of the plateau was found to be much broader, ranging between $30 \mathrm{~K}$ and $110 \mathrm{~K}$. The value of $\kappa(T)$ was low but about 2.5 times higher in the plateau region as compared to p-CNB. Similarly, when temperature increases from $110 \mathrm{~K}$ till the highest temperature of the measurements, ca. $260 \mathrm{~K}\left(>T_{\mathrm{g}}=191 \mathrm{~K}\right), \kappa(T)$ exhibits an anomalous growth. 


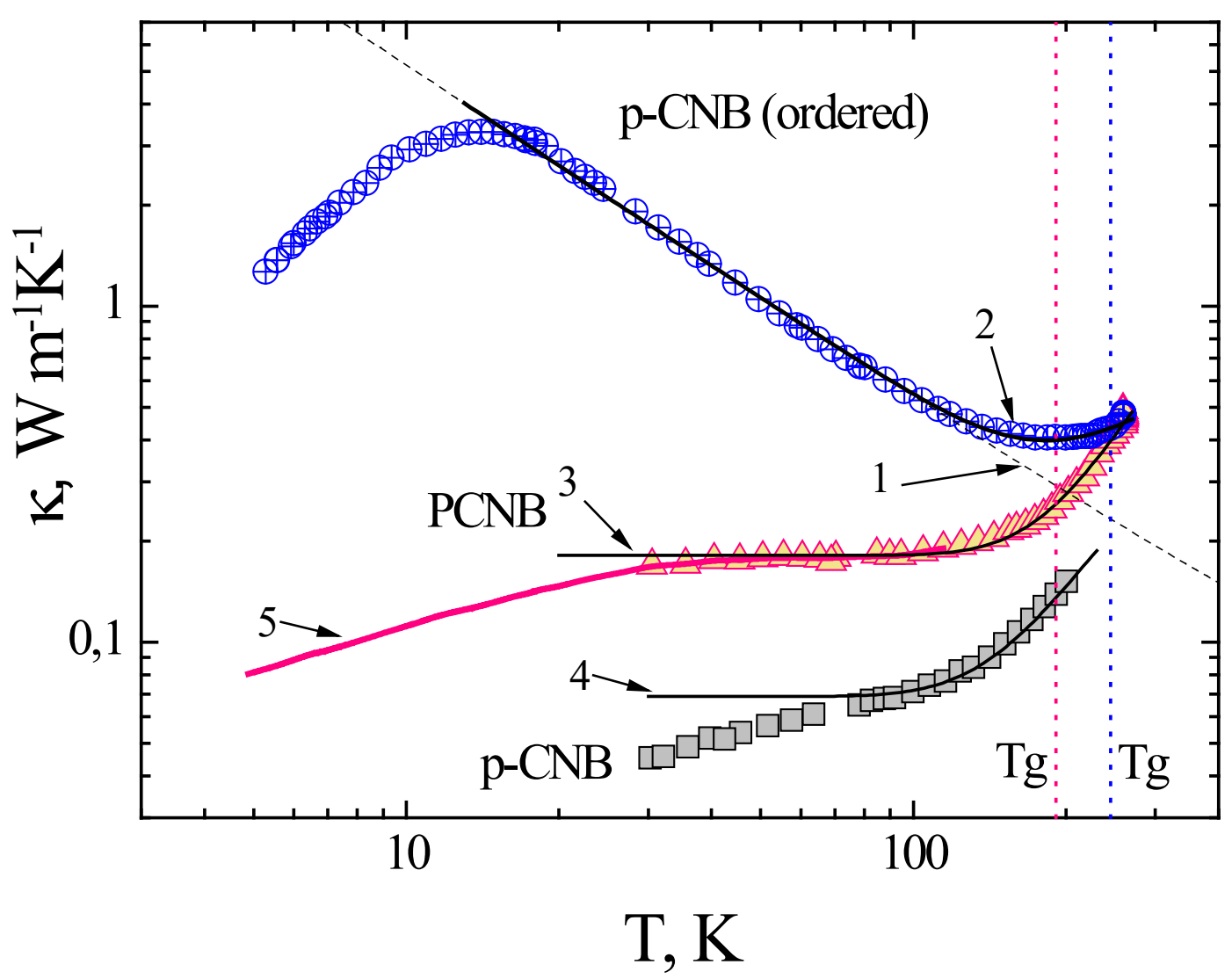

Fig.1. The temperature dependence of the thermal conductivity of the investigated crystals: p-CNB - orientationally ordered (O); orientationally disordered ( $\boldsymbol{\square})$; PCNB - orientationally disordered ( $\mathbf{\Delta})$. Lines: (1) - $\kappa_{1}(T)=A / T+B ;(2,3,4)-\kappa(T)=\kappa_{1}(T)+\kappa_{\mathrm{TA}}(T)$, where $\kappa_{\mathrm{TA}}(T)=\kappa_{0} \exp \left(-E / k_{B} T\right)$. The parameters $A, B, E$ and $\kappa_{0}$ are shown in Table 1. Pink solid line (5) is smoothed data of PCNB [27]. Vertical dotted lines are the glass transition temperatures for p-CNB (blue line) and PCNB (pink line).

The measured thermal conductivities of freons in the orientational glass state and in the orientationally disordered phase are illustrated in Fig. 2 in $\log -\log$ scale. The values of the thermal conductivity of two F-112 samples, obtained with two different setups are virtually the same within the temperature range $110-200 \mathrm{~K}$. The values measured on sample 1 of F-112 in the temperature range $20-140 \mathrm{~K}$ are virtually the same as those previously reported below $100 \mathrm{~K}$ [41] and $140 \mathrm{~K}$ [33], these data are also shown in Fig. 2, for comparison. The figure also shows the glass transition temperatures $T_{\mathrm{g}}$ for F-112 and F-113 (vertical dotted lines). 


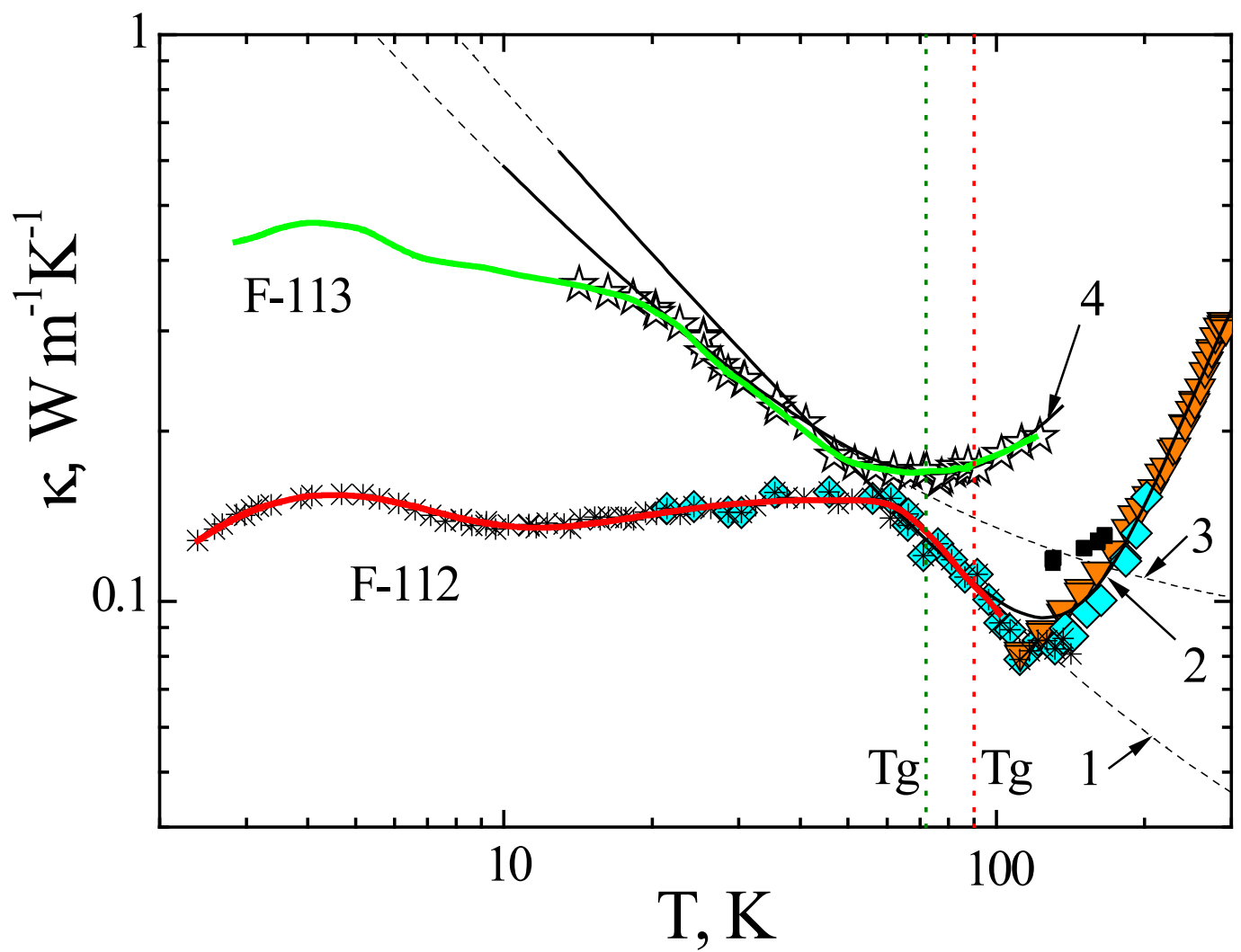

Fig. 2. The temperature dependence of the thermal conductivity of freon crystals. F-112: this work, samples $1(\diamond)$, and $2(\boldsymbol{\nabla}), *$ is data from [33]. F-113: this work (stars). $\boldsymbol{\square}$ is data [42] for freon HFC-134a. Lines: $(1,3)-\kappa_{1}(T)=A / T+B ;(2,4)-\kappa(T)=\kappa_{1}(T)+\kappa_{\mathrm{TA}}(T)$, where $\kappa_{\mathrm{TA}}(T)=\kappa_{0} \exp \left(-E / k_{B} T\right)$. The parameters $A, B, E$ and $\kappa_{0}$ are given in Table 1. Color solid lines are smoothed data of F-112 [41] (red line) and F-113 [33] (green line). Straight dotted lines are the glass transition temperatures for F-112 (red line) and F-113 (green line).

At low temperatures in case of F-112 $\kappa(T)$ displays the typical glasslike behavior: on increasing temperature from $20 \mathrm{~K}$ to $60 \mathrm{~K}, \kappa(T)$ has a plateau and then decreases to a minimum, $\kappa_{\min } \approx 0.08 \mathrm{~W} \mathrm{~m}^{-1} \mathrm{~K}^{-1}$, at $T_{\min } \approx 112 \mathrm{~K}\left(>T_{\mathrm{g}}=90 \mathrm{~K}\right)$. The thermal conductivity of F-112 increases anomalously above $T_{\min }$ up to the highest temperature of measurement, $T=290 \mathrm{~K}$, reaching a value of ca. $0.3 \mathrm{~W} \mathrm{~m}^{-1} \mathrm{~K}^{-1}$. The experimental findings for $\mathrm{F}-113$ across the temperature range $14 \mathrm{~K}-123 \mathrm{~K}\left(>T_{\mathrm{g}}=72 \mathrm{~K}\right)$ coincide with earlier measurements at low temperature [33] (smoothed values are shown in Fig. 2 solid color line). When increasing temperature from $14 \mathrm{~K}$ to $77 \mathrm{~K}$, the thermal conductivity first drops to its minimum $\kappa_{\min } \approx 0.16 \mathrm{~W} \mathrm{~m}^{-1} \mathrm{~K}^{-1}$, i.e. exhibits a crystal-like behavior, as in $\mathrm{F}-112$, and then starts to grow 
anomalously with temperature. Here it must be emphasized that in [42] also the growth of $\kappa(T)$ of freons HFC-32, HFC-125, and HFC-134a in the temperature region near the melting was noted. For comparison, Fig. 2 shows the literature data [42] for freon HFC-134a. In freons F-112 and F-113 at temperatures above the low-temperature plateau, a feature is observed in the form of a shoulder-like abrupt change in the slope of the curve $\kappa(T)$. This feature can be associated with thermal activation jumps between orientational states similar to those in $\mathrm{C}_{60}$ crystals [43]. However, our work is aimed at studying the anomalous behavior of $\kappa(T)$ in the temperature region above $T_{\mathrm{g}}$.

Note that $\kappa(T)$ of the orientationally ordered crystal p-CNB and orientational glasses F-112 and F-113 exhibits a normal behavior in the temperature regions $T=15 \mathrm{~K}-115 \mathrm{~K}, 60 \mathrm{~K}$ $112 \mathrm{~K}$ and $18 \mathrm{~K}-60 \mathrm{~K}$, respectively, but changes anomalously at higher temperatures (see Figs. 1 and 2). The normal behavior is mainly governed by phonon - phonon scattering and the anomalous changes are attributed to a new mechanism of heat transfer by high-energy excitations [11].

The high temperature behavior of $\kappa(T)$ in molecular crystals within the temperature interval where phonon-phonon scattering is dominant is currently approximated by a sum of two independent contributions, phonons and diffusons [2, 6, 8, 10-13]:

$$
\kappa_{1}(T)=A / T+B .
$$

The term $A / T$ is the contribution of the three-phonon processes of scattering (propagating phonons), while the term $B$, temperature-independent, describes additional heat transfer by localized excitations (diffusons). The contributions $A$ (phonon) and $B$ (diffusive) can readily be determined by plotting the product $T \cdot \kappa(T)$ as a function of temperature (not shown). Table 1 collects the obtained $A$ and $B$ values for the studied phases through eq. (1) for the orientationally ordered crystal p-CNB and orientational glasses F-112, F-113 in the temperature regions $15 \mathrm{~K}$ $115 \mathrm{~K}, 60 \mathrm{~K}-112 \mathrm{~K}$ and $18 \mathrm{~K}-60 \mathrm{~K}$, respectively. The dependence $\kappa_{1}(T)$ is shown in Figs. 1 and 2 (dashed lines). The parameter $A$ describes the intensity of the processes of phonon scattering. In the orientationally ordered p-CNB the phonon processes, described by the $A$ parameter, are much more relevant than in freons F-112 and F-113 (see Table 1). In F-112 and F-113 these processes are close in magnitude and fully agree with previous published data [33]. Eq. (1) is also suitable to describe the behavior of the thermal conductivity in orientationally disordered phases of pCNB and PCNB in the temperature interval in which the $\kappa(T)$ "plateau" extends. However, in this case the first term is $A=0 \mathrm{~W} \mathrm{~m}^{-1}$ because phonon-phonon scattering is absent in those orientationally disordered phases for which such a disorder concerns exclusively rotations around one axis (in both cases perpendicular to the benzene ring). 
The increase of $\kappa(T)$ with temperature was for the first time observed in triclinic parabromobenzophenone polymorph [11]. It was attributed to a new mechanism of heat transfer due to intramolecular modes which are thermally activated in the temperature interval where phononphonon scattering is dominant. Later on, a similar effect was observed in monoclinic parabromobenzophenone polymorph [12]. A slight thermally activated increase of thermal conductivity in the high temperature region has also been observed in non-bromizated benzophenone compound in its stable orthorhombic $\alpha$-form [13].

The contribution of intramolecular modes can be described within a simple model in which a thermally activated contribution $\kappa_{\mathrm{TA}}(T)$ to the thermal conductivity is approximated by an Arrhenius law with activation energy $E$ [11-13]:

$$
\kappa_{\mathrm{TA}}(T)=\kappa_{0} \exp \left(-E / k_{B} T\right)
$$

where $\kappa_{0}$ is the pre-exponential factor characterizing the intensity of the thermally activated heat transfer and $k_{B}$ is the Boltzmann constant. The pre-exponential factor $\kappa_{0}$ and the activation energy $E$ of the studied samples were determined following the same procedure as that used in [11-13]. Thermal conductivity, neglecting the contribution of low temperature defects, can be described as:

$$
\kappa(T)=\kappa_{1}(T)+\kappa_{\mathrm{TA}}(T) .
$$

Thus, by subtracting the $\kappa_{1}(T)$ contribution to the total thermal conductivity, $\kappa(T)$, the temperature dependence of $\kappa_{\mathrm{TA}}(T)$ can be analyzed by plotting $\ln \left(\kappa_{\mathrm{TA}}(T)\right)$ vs $1 / T$. The results obtained were approximated by a straight line of $\ln \left(\kappa_{\mathrm{TA}}\right)$ vs $T^{-1}$, regardless the glass transition temperature value. The slope of the straight line contains the activation energy $E$ in Eq. (2). As an example, such a plot is illustrated for freon F-112 in Fig. 3. It clearly shows that the function provides a good description of the experimental results in the high temperature region $135 \mathrm{~K}-$ $290 \mathrm{~K}$. 


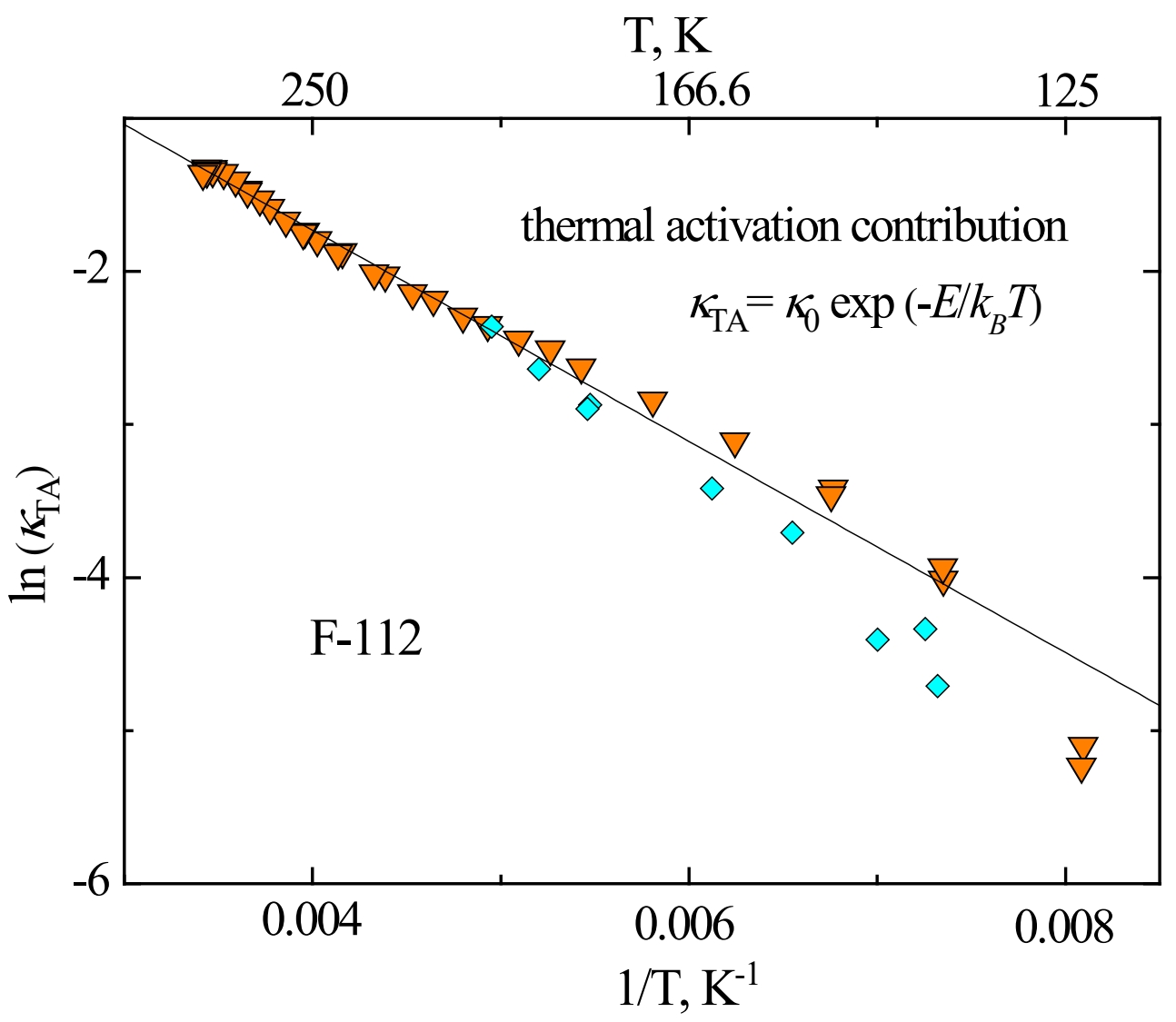

Fig. 3. The semi-logarithmic plot of the thermally activated contribution for two F-112 samples. Symbols (identical to those in Fig. 2) - experimental results. The straight line is the dependence $\ln \left(\kappa_{\mathrm{TA}}\right)$ versus $T^{-1}, E=690 \mathrm{~K}$ is the activation energy, $\kappa_{0}=2.8 \mathrm{~W} \mathrm{~m}^{-1} \mathrm{~K}^{-1}$.

Following the described procedure, the dependences $\kappa(T)$ are illustrated as solid lines in Fig. 1 for the orientationally ordered crystal p-CNB $(T>15 \mathrm{~K})$, the orientationally disordered p-CNB and PCNB ( $T>77 \mathrm{~K}$ and $T>30 \mathrm{~K}$, respectively), and Fig. 2 for F-112 ( $T>60 \mathrm{~K})$ and F$113(T>18 \mathrm{~K})$; the parameters $A, B, E$ and $\kappa_{0}$ are gathered in Table 1.

\section{Discussion}

The anomalous behavior of thermal conductivity can be attributed to an additional effect, thermally activated, of some intramolecular modes. According to the model of thermally stimulated hopping [11], not only standard phonons and diffusons, but also high-frequency localized modes (e.g., intramolecular modes of flexible molecules and other localized excitations) can act as heat transfer agents. The heat transport is generated through the interaction of ordinary vibrational modes of the acoustic branch and localized vibrational excitations [3]. 
In terms of the new approach based on the analysis of the Green - Kubo modes, it is shown for simple systems [44, 45] that the contribution of intramolecular modes to thermal conductivity depends on a great variety of factors, such as crystal structure, anharmonicity of molecular interactions, degrees of coupling (hybridization) of vibrational, rotational, intramolecular modes and so on.

The anomalous behavior of high-temperature thermal conductivity in parabromobenzophenone polymorphs $[11,12]$ and orthorhombic benzophenone ( $\alpha$ - form) [13] was interpreted on the basis of thermally stimulated hopping of excitations. It was assumed that the heat transport in these materials was performed through intramolecular vibrations of the flexible molecules of benzophenone and its derivatives.

A thermally activated contribution (activation energy $E=700 \mathrm{~K}$ ) to the thermal conductivity was also detected in the stable orientationally ordered orthorhombic phase of 2-adamantanone $\left(\mathrm{C}_{10} \mathrm{H}_{14} \mathrm{O}\right)$ [18]. The effect was attributed to the thermally stimulated hopping of low-energy excitations.

In this study the measured thermal conductivity is described using Eq. (3) for the monoclinic disordered phase of 2-adamantanone $\left(T_{\mathrm{g}}=132 \mathrm{~K}\right.$ [46]). Eq. (3) was also used to describe the thermal conductivities of orthorhombic and monoclinic phases of 2-adamantanone [18] (see the parameters $A, B, \kappa_{0}$ and $E$ in Table 1). The parameter $A=15 \mathrm{~W} \mathrm{~m}^{-1}$ accounts for the intensity of phonon-phonon scattering in the monoclinic disordered phase. In the orthorhombic ordered phase, most likely, the phonon-phonon interaction is completely masked by scattering of phonons by defects, which is not surprising: the monoclinic sample was a goodquality coarse-grained polycrystal, while the orthorhombic ordered phase prepared by a thermal cycling procedure gave rise to a highly defected structure, especially at the grain boundaries and dislocations [18]. This may be the reason why the diffuse contribution (parameter $B$ ) in the monoclinic disordered phase exceeds by three times that of the orthorhombic one. In the monoclinic phase the activation energy $E$ is about 1.3 times higher and the pre-exponential factor $\kappa_{0}$ is 2.2 times lower than the corresponding value in the orthorhombic phase. The anomalous increase in the thermal conductivities of the two 2-adamantanone polymorphs is evidenced by the increase of their heat capacities with temperature [18]. Although the polymorphs have different thermoconducting properties, the temperature dependences of their heat capacities are close in behavior and value. In the high temperature region the heat capacity increases linearly with temperature, which is reasonable since the heat capacity contributions come from all kinds of excitations, including the local excitations inherent in the molecule itself.

The activation energy of the orientationally ordered crystal p-CNB is $E=550 \pm 40 \mathrm{~K}$ $\left(382 \pm 36 \mathrm{~cm}^{-1}\right)$. In the orientationally disordered p-CNB $E=650 \pm 50 \mathrm{~K}\left(451 \pm 35 \mathrm{~cm}^{-1}\right)$. The 
values of the activation energy $E$ in the orientationally ordered and the orientationally disordered p-CNB crystals differ only slightly (within the accuracy of measurements). Apparently, in the case of $\mathrm{p}-\mathrm{CNB}$, the activation energy can be associated with closely spaced modes: either with torsion mode $\left(E=401 \mathrm{~cm}^{-1}\right)$ or with wagging mode $\left(E=468 \mathrm{~cm}^{-1}\right)$ of the nitro-group of the flexible molecule p-CNB [47].

In the case of an orientationally disordered PCNB crystal, the value of the activation energy is $E=900 \pm 50 \mathrm{~K}$, quite different from the activation energy of crystal p-CNB. This is probably due to the fact that the replacement of four hydrogen atoms in the p-CNB molecule by four chlorine atoms leads to an increase in the strength of the bonds between the nearest neighbors in the crystal. This can effectively make the PCNB molecule more rigid than the p-CNB molecule.

The activation energy in freon F-112 is $E \approx 690 \mathrm{~K}\left(\approx 480 \mathrm{~cm}^{-1}\right)$. Our value is close to the absorption frequencies corresponding to lines $471 \mathrm{~cm}^{-1}$ and $482 \mathrm{~cm}^{-1}$ in the IR transmission spectra taken on liquid and solid F-112 [48].

As for the activation energy in freon F-113 a value of $E \approx 300 \mathrm{~K}\left(\approx 208 \mathrm{~cm}^{-1}\right)$ is obtained. The harmonic frequencies and intensities of bond vibrations for such a molecule were calculated in terms of the density functional theory for two F-113 conformers [49]. It was shown that the vibrational frequencies corresponding to rocking of the $\mathrm{CFCl}_{2}$ and $\mathrm{CF}_{2} \mathrm{Cl}$ groups and bending of the $\mathrm{Cl}-\mathrm{C}-\mathrm{C}-\mathrm{Cl}$ bonds in the $\mathrm{F}-113$ molecule are close to our values. The activation energy in F-112 is greater than for F-113. We draw attention to the fact that the activation energy of a group of similar substances is higher the higher the melting point. For example, $E$ and $T_{\mathrm{m}}$ for F112 is greater than for F-113 and the same relationship holds for PCNB and p-CNB.

The recent data on the thermal conductivity of crystalline 1 -F-adamantane, $T_{\mathrm{g}}=92 \mathrm{~K}[50$, 51] also evidence a thermally activated increase of thermal conductivity in the high temperature region. Experimental results on thermal conductivity can be also described by Eq. (3) (see $A, B$, $\kappa_{0}$ and $E$ for 1-F-adamantane in Table 1).

Of interest is the correlation between the pre-exponential factor $\kappa_{0}$ and the activation energy $E$. Fig. 4 illustrates the dependence $\kappa_{0}(E)$ : circles are the experimental results taken from the substances analyzed here and the solid red straight line is the dependence $\kappa_{0}(E)=\beta\left(E / E_{\min }\right.$ 1), where $\beta=0.98 \pm 0.05 \mathrm{~W} \mathrm{~m}^{-1} \mathrm{~K}^{-1}$ and $E_{\min }=165 \pm 10 \mathrm{~K}$ is the threshold energy, below which the thermal activation mechanism does not appear due to hopping of excitations. This means that for the thermoactivation mechanism to take place it is necessary that the energy of localized excitations be greater than the limiting energy of the phonon spectrum. The pre-exponential factors $\kappa_{0}$ of two 4-BrBP polymorphs and two phases of p-CNB are shown in Fig.4 (different symbols). It is seen that $\kappa_{0}$ is positive above the threshold energy $E_{\min }$, which suggests that the 
thermal activation process is launched by the non-propagating locon vibrations $[45,52]$ whose frequencies are beyond the threshold frequency and above the Debye phonon spectrum. The vibrations at frequencies below the threshold frequency (propagons, diffusons) do not contribute to the thermal activation process. This is also evident from the very low Debye temperature $\Theta_{\mathrm{D}}<E_{\min }$ of some analyzed substances (see Table 1). It has recently been demonstrated that localized modes (locons) are the responsible of the thermal conductivity increase at high temperature for amorphous $\mathrm{SiO}_{2}[52]$.

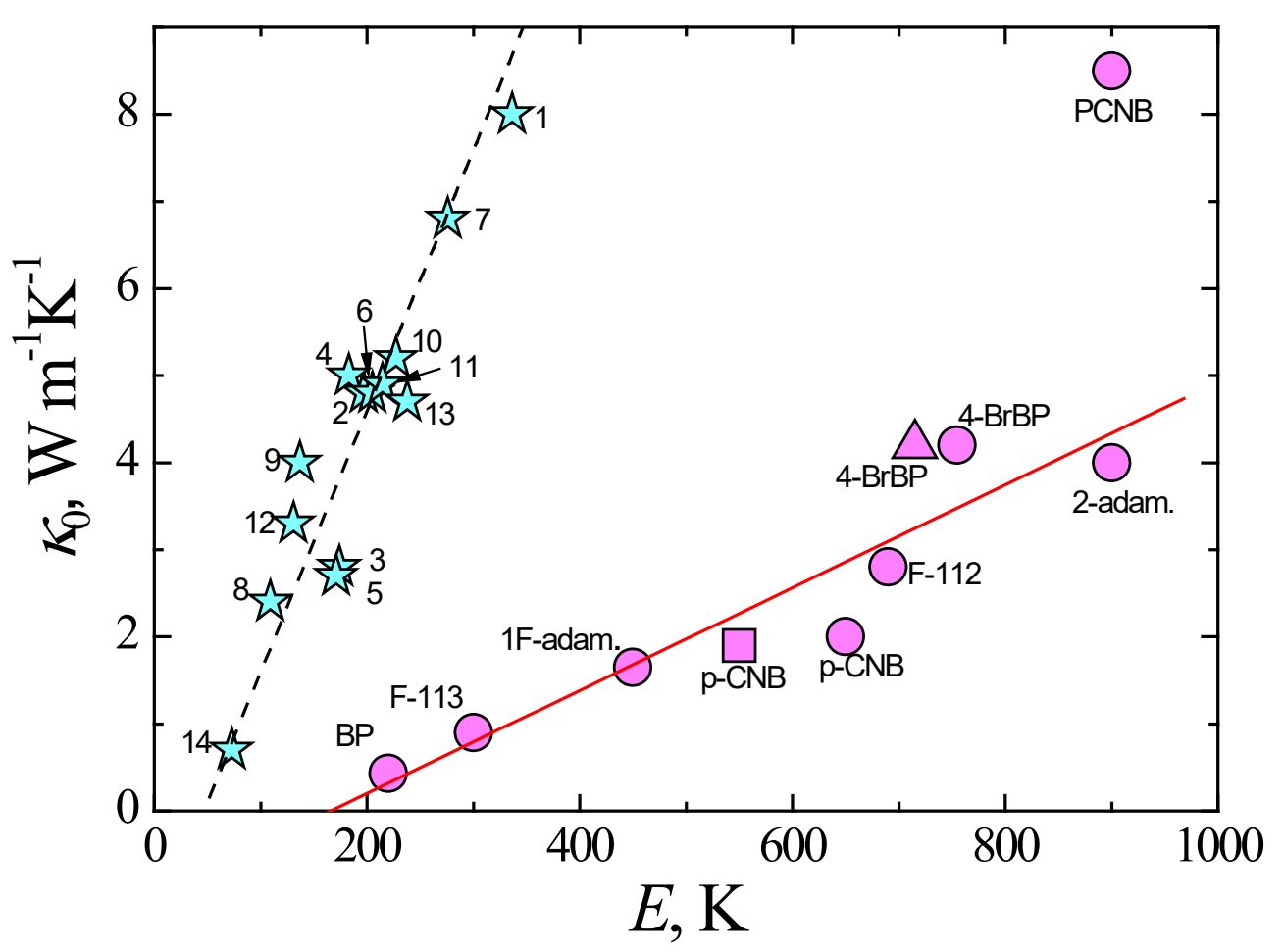

Fig.4. The pre-exponential factor $\kappa_{0}$ versus the activation energy $E$ for molecular compounds studied by us, and for quasicrystals according to the literature data. Symbols: circles are the experimental results of molecular substances, $(\boldsymbol{\square})$ - orientationally ordered p-CNB, ( $\mathbf{\Delta})$ triclinic 4-BrBP polymorph. The stars correspond to the data for quasicrystals, the numbers in the figure indicate the chemical composition: $1-\mathrm{i}-\mathrm{Al}_{72} \mathrm{Pd}_{19.5} \mathrm{Mn}_{8.5}$ [5]; $2-\mathrm{Al}_{73} \mathrm{Mn}_{27}$ [54]; $3-$ $\mathrm{APFe}_{7}$ [55]; 4 - $\mathrm{APCo}_{15.5}$ [55]; 5 - $\mathrm{ARh}_{24}$ [55]; 6 - T-Al ${ }_{73} \mathrm{Mn}_{27}$ [56]; 7 - T- $-\mathrm{Al}_{73} \mathrm{Mn}_{25} \mathrm{Pd}_{2}$ [56]; 8 $\mathrm{T}-\mathrm{Al}_{73} \mathrm{Mn}_{23} \mathrm{Pd}_{4}$ [56]; $9-\mathrm{T}-\mathrm{Al}_{73} \mathrm{Mn}_{21} \mathrm{Pd}_{6}$ [56]; $10-\mathrm{T}-\mathrm{Al}_{73} \mathrm{Mn}_{25} \mathrm{Fe}_{2}$ [57]; $11-\mathrm{T}-\mathrm{Al}_{73} \mathrm{Mn}_{23} \mathrm{Fe}_{4}$ [57]; $12-\mathrm{d}-\mathrm{Al}_{73} \mathrm{Mn}_{21} \mathrm{Fe}_{6}$ [57]; $13-\mathrm{APFe}_{2}$ [55]; $14-\mathrm{Al}_{64} \mathrm{Cu}_{23} \mathrm{Fe}_{13}$ [58]. The straight lines are the dependencies $\kappa_{0}(E)=\beta\left(E / E_{\min }-1\right)$. Meaning ofof parameters $E_{\min }$ and $\beta$ are given in the text. 
The dependence of $\kappa_{0}$ on $E_{\min }$ is unexpected, but the fact that this dependence does not exist in the whole energy range, but beginning with some threshold energy, most likely, is determined by the interaction of isolated localized excitations of soft molecules with excitations of continuous acoustic spectrum. Apparently, such an interaction is associated with strong anharmonicity of some modes of vibrational motion of soft molecules in a crystal. It should be emphasized that the linear approximation $\kappa_{0}(E)$ describes well the experimental data of the studied substances at small values of the activation energy. In the case of orthorhombic 2-adamantanone and PCNB, a deviation from the linear dependence is observed.

Note that the modes which do not interact with one another or other vibrational modes have no noticeable effect on thermal conductivity. The anomalous increase of thermal conductivity was also observed in the anisotropic crystal $\mathrm{CsDy}\left(\mathrm{MoO}_{4}\right)_{2}$ [53] and in quasicrystals $[4,5,7,54-58]$. Such increase was explained qualitatively by the process of hybridization between different types of excitations. Figure 4 shows the dependence $\kappa_{0}(E)$ for a group of quasicrystals: stars are the experimental results taken from [5, 54-58]. These experimental data are well described by a linear dependence $\kappa_{0}(E)=\beta\left(E / E_{\min }-1\right)$, dash black line, where $\beta=1.4 \pm 0.1 \mathrm{~W} \mathrm{~m}^{-1} \mathrm{~K}^{-1}$ and $E_{\min }=46.7 \pm 3 \mathrm{~K}$ is the threshold energy for quasicrystals. It can be seen that in the region of low activation energies, both for molecular substances and for the case of quasicrystals, a linear dependence of the pre-exponential factor on the activation energy of the same type is observed.

\section{Conclusions}

The temperature dependence of thermal conductivity has been investigated by the steadystate linear heat flow method. The materials were specially selected as molecular polycrystals consisting of flexible molecules: $\mathrm{p}-\mathrm{CNB}$ in orientationally disordered $(T=30 \mathrm{~K}-220 \mathrm{~K}$, $\left.T_{\mathrm{g}}=245 \mathrm{~K}\right)$ and orientationally ordered $(T=9 \mathrm{~K}-260 \mathrm{~K})$ phases, PCNB in an orientationally disordered phase $\left(T=30 \mathrm{~K}-260 \mathrm{~K}, T_{\mathrm{g}}=191 \mathrm{~K}\right)$ and in an orientational glass and plastic phases of freons F-112 ( $\left.T=20 \mathrm{~K}-290 \mathrm{~K}, T_{\mathrm{g}}=90 \mathrm{~K}\right)$ and F-113 $\left(T=14 \mathrm{~K}-123 \mathrm{~K}, T_{\mathrm{g}}=72 \mathrm{~K}\right)$ in the high-temperature dynamic disordered phase as well as in the orientational glass domain. The new results show that along with its usual behavior at low-temperature, the thermal conductivity of the investigated substances exhibits an anomalous increase at high temperatures. In a wide interval of temperatures the thermal conductivity of ordered p-CNB $(16 \mathrm{~K}-260 \mathrm{~K})$, disordered p-CNB $\left(75 \mathrm{~K}-218 \mathrm{~K}, T_{\mathrm{g}}=245 \mathrm{~K}\right)$, disordered PCNB $\left(30 \mathrm{~K}-259 \mathrm{~K}, T_{\mathrm{g}}=191 \mathrm{~K}\right), \mathrm{F}-112$ $\left(55 \mathrm{~K}-290 \mathrm{~K}, T_{\mathrm{g}}=90 \mathrm{~K}\right)$ and $\mathrm{F}-113\left(18 \mathrm{~K}-123 \mathrm{~K}, T_{\mathrm{g}}=72 \mathrm{~K}\right)$ can be described as the result of two terms, $\kappa(T)=\kappa_{1}(T)+\kappa_{\mathrm{TA}}(T)$. The first term $\kappa_{1}(T)=A / T+B$ accounts for the contributions of phonon-phonon scattering $(A / T)$ and the temperature-independent $B$ presents an additional 
mechanism of heat transfer induced by diffuse phonon scattering. Phonon-phonon scattering is absent in disordered $\mathrm{p}-\mathrm{CNB}$ and PCNB. The term $\kappa_{\mathrm{TA}}(T)$ is a thermally activated contribution with activation energy $E$. It is described by the Arrhenius equation $\kappa_{\mathrm{TA}}(T)=\kappa_{0} \exp \left(-E / k_{B} T\right)$. The results obtained are compared with the data taken for other crystals exhibiting an anomalous increase in thermal conductivity with temperature. It has been found that in molecular crystals (in orientationally ordered, orientationally disordered, with different structures) formed by flexible molecules, an increase of $\kappa(T)$ with increasing temperature is observed in the hightemperature region. This increasing is typical for the thermal activation mechanism of heat transfer by low-energy localized molecular excitations. In addition, it is found that the preexponential factor $\kappa_{0}$ is linearly dependent on the activation energy, an experimental fact that reveals the existence of an energy threshold for the thermally activated new mechanism of heat transport.

The new mechanism is initiated by thermally stimulated hopping of excitations, presumably related to intramolecular vibrations of the group $\mathrm{NO}_{2}$ in $\mathrm{p}-\mathrm{CNB}$, rocking of the groups $\mathrm{CFCl}_{2}$ and $\mathrm{CF}_{2} \mathrm{Cl}$ in $\mathrm{F}-113$ and/or strongly anharmonic excitations. The results obtained are compared with literature data on intramolecular vibrational energy. The information derived extends our knowledge of the nature of thermally stimulated heat transfer in molecular crystals, especially those displaying some kind of disorder for which straightforward calculations from first principles cannot provide phonon velocities and thus prediction of thermal conductivity is not possible. 
Table 1. The parameters $A, B, E$ and $\kappa_{0}$ in Eqs. (1), (2) and (3) used to describe the temperature dependence of the thermal conductivity coefficient in the investigated substances: $\Delta T$ is the temperature interval in which the experimental results are well described by Eq. (3); $\Theta_{\mathrm{D}}$ is the Debye temperature; $T_{\mathrm{g}}$ is the glass transition temperature; $T_{\min }$ is the temperature at the thermal conductivity minimum. For comparison, see the corresponding parameters for two 4-bromobenzophenone polymorphs [11, 12], benzophenone [13], two 2-adamantanone polymorphs $[18,46]$ and 1-F-adamantane [51].

\begin{tabular}{|c|c|c|c|c|c|c|c|c|}
\hline & & & $\kappa_{1}(T)$ & $\kappa_{\mathrm{TA}}$ & & & & \\
\hline Substance & $\Delta T, \mathrm{~K}$ & $\begin{array}{c}A, \\
\mathrm{~W} \mathrm{~m}^{-1}\end{array}$ & $\begin{array}{c}, \\
\mathrm{W} \mathrm{m}^{-1} \mathrm{~K}^{-1}\end{array}$ & $\begin{array}{c}\kappa_{0}, \\
\mathrm{~W} \mathrm{~m} \mathrm{~m}^{-1} \mathrm{~K}^{-1}\end{array}$ & $\begin{array}{c}E, \\
\text { К }\end{array}$ & $\begin{array}{c}\Theta_{\mathrm{D}} \\
\mathrm{K}\end{array}$ & $\begin{array}{c}T_{\mathrm{g}}, \\
\mathrm{K}\end{array}$ & $\begin{array}{c}T_{\min }, \\
\mathrm{K}\end{array}$ \\
\hline $\begin{array}{c}\mathrm{p}-\mathrm{CNB}, \\
\text { orientationally } \\
\text { ordered }\end{array}$ & $16-260$ & $52 \pm 1$ & $0.02 \pm 0.005$ & $1.9 \pm 0.3$ & $550 \pm 40$ & & - & $\approx 188$ \\
\hline $\begin{array}{c}\mathrm{p}-\mathrm{CNB}, \\
\text { orientationally } \\
\text { disordered }\end{array}$ & $75-218$ & 0 & $0.0688 \pm 0.005$ & $2 \pm 0.5$ & $650 \pm 50$ & & $\begin{array}{l}245 \\
{[22,} \\
23]\end{array}$ & - \\
\hline $\begin{array}{c}\text { PCNB, } \\
\text { orientationally } \\
\text { disordered }\end{array}$ & $30-259$ & 0 & $0.181 \pm 0.005$ & $8.5 \pm 1.5$ & $900 \pm 50$ & $\begin{array}{c}66 \\
{[27]}\end{array}$ & $\begin{array}{l}\approx 191 \\
{[24]}\end{array}$ & - \\
\hline $\mathrm{F}-112$ & $55-290$ & $\begin{array}{c}7.8 \pm 0.3 \\
{[33]}\end{array}$ & $\begin{array}{c}0.02 \pm 0.003 \\
{[33]}\end{array}$ & $2.8 \pm 0.5$ & $690 \pm 50$ & $\begin{array}{c}76 \\
{[41]}\end{array}$ & $\begin{array}{l}\approx 90 \\
{[29]}\end{array}$ & $\approx 112$ \\
\hline $\mathrm{F}-113$ & $18-123$ & $\begin{array}{c}5.0 \pm 0.2 \\
{[33]}\end{array}$ & $\begin{array}{c}0.085 \pm 0.005 \\
{[33]}\end{array}$ & $0.9 \pm 0.2$ & $300 \pm 30$ & $\begin{array}{c}80 \\
{[33]}\end{array}$ & $\begin{array}{l}\approx 72 \\
{[33]}\end{array}$ & $\approx 75$ \\
\hline 4-BrBP, triclinic & $8-303$ & $\begin{array}{c}29.5 \pm 1.0 \\
{[11]}\end{array}$ & $\begin{array}{c}0.21 \pm 0.05 \\
{[11]}\end{array}$ & $\begin{array}{c}4.2 \pm 0.5 \\
{[11]}\end{array}$ & $\begin{array}{c}715 \pm 50 \\
{[11]}\end{array}$ & & - & $\begin{array}{r}\approx 150 \\
\quad[11]\end{array}$ \\
\hline $\begin{array}{l}\text { 4-BrBP, } \\
\text { monoclinic }\end{array}$ & $30-320$ & $\begin{array}{c}15 \pm 1.0 \\
{[12]}\end{array}$ & $\begin{array}{c}0.15 \pm 0.05 \\
{[12]}\end{array}$ & $\begin{array}{c}4.2 \pm 0.5 \\
{[12]}\end{array}$ & $\begin{array}{c}755 \pm 50 \\
{[12]}\end{array}$ & & - & $\begin{array}{l}\approx 120 \\
{[12]}\end{array}$ \\
\hline $\begin{array}{c}\text { Benzophenone } \\
{[13]}\end{array}$ & $11-270$ & $\begin{array}{c}12 \pm 1.5 \\
{[13]}\end{array}$ & $\begin{array}{c}0.16 \pm 0.06 \\
{[13]}\end{array}$ & $\begin{array}{c}0.43 \pm 0.02 \\
{[13]}\end{array}$ & $\begin{array}{c}220 \pm 20 \\
{[13]}\end{array}$ & & - & $\begin{array}{l}\approx 100 \\
{[13]}\end{array}$ \\
\hline $\begin{array}{l}\text { 2-adamantanone, } \\
\text { monoclinic [18] }\end{array}$ & $35-200$ & $15 \pm 0.5$ & $0.355 \pm 0.01$ & $4 \pm 0.5$ & $900 \pm 50$ & $\begin{array}{l}124.4 \\
{[18]}\end{array}$ & $\approx 132$ & $\begin{array}{r}\approx 160 \\
{[18]}\end{array}$ \\
\hline $\begin{array}{l}\text { 2-adamantanone, } \\
\text { orthorhombic [18] }\end{array}$ & $29-185$ & 0 & $0.12 \pm 0.003$ & $9 \pm 0.5$ & $\begin{array}{r}700 \\
{[18]}\end{array}$ & $\begin{array}{l}124.4 \\
{[18]}\end{array}$ & - & - \\
\hline
\end{tabular}


$\begin{array}{llllll}\text { l-F-adamantane } & 20-210 & 4.5 \pm 0.1 & 0.19 \pm 0.005 & 1.65 \pm 0.3 & 450 \pm 30\end{array}$

$92.3 \approx 90$

[51] 


\section{References}

[1] R. Berman, Thermal Conductivity in Solids, Clarendon, Oxford, 1976.

[2] V. A. Konstantinov, V. G. Manzhelii, M. A. Strzhemechny, S. A. Smirnov, The 1 1/T low and isochoric thermal conductivity of rare gas solids, Fiz. Nizk. Temp. 14 (1988) 90-100 (Low Temp. Phys. 14 (1988) 48-58).

[3] S. Alexander, O. Entin-Wohlman, R. Orbach, Phonon-fracton anharmonic interactions: The thermal conductivity of amorphous materials, Phys. Rev. B 34 (1986) 2726-2734.

[4] C. Janot, Conductivity in quasicrystals via hierarchically variable-range hopping, Phys. Rev. B 53 (1996) 181-191.

[5] A. Bilušić, A. Smontara, J. Dolinšek, P. McGuiness, H.R. Ott, Phonon scattering in quasicrystalline $\mathrm{i}-\mathrm{Al}_{72} \mathrm{Pd}_{19.5} \mathrm{Mn}_{8.5}$ : A study of the low-temperature thermal conductivity, J. Alloys Compd. 432 (2007) 1-6.

[6] A.I. Krivchikov, F.J. Bermejo, I.V. Sharapova, O.A. Korolyuk, and O.O. Romantsova, Experimental evidence of the role of quasilocalized phonons in the thermal conductivity of simple alcohols in orientationally ordered crystalline phases, Fiz. Nizk. Temp. 35 (2009) 11431150 (Low Temp. Phys. 35 (2009) 891-897.

[7] P. Popčević, D. Stanić, Ž. Bihar, A. Bilušić, A. Smontara, Heat Transport in AluminumBased Quasicrystals i-AlPdMn, i-AlCuFe, and d-AlCoNi, Israël J. Chem. 51 (2011) 1340-1348.

[8] O. A. Korolyuk, Thermal conductivity of molecular crystals of monoatomic alcohols: from methanol to butanol, Fiz. Nizk. Temp. 37 (2011) 526-530 (Low Temp. Phys. 37 (2011) 416420.

[9] A. I. Krivchikov, O. A. Korolyuk, I. V. Sharapova, J. L. Tamarit, F. J. Bermejo, L. C. Pardo, M. Rovira-Esteva, M. D. Ruiz-Martin, A. Jeżowski, J. Baran, N. A. Davydova, Effects of internal molecular degrees of freedom on the thermal conductivity of some glasses and disordered crystals, Phys. Rev. B 85 (2012) 014206.

[10] A. I. Krivchikov, O. O. Romantsova, O. A. Korolyuk, G. A. Vdovichenko, Yu. V. Horbatenko, The specific features of heat transfer in the orientationally ordered phases of molecular crystals in the region with predominant phonon-phonon scattering, Fiz. Nizk. Temp. 41 (2015) 708-717 (Low Temp. Phys. 41 (2015) 551-556.

[11] M. A. Strzhemechny, A. I. Krivchikov, A. Jeżowski, D. I. Zloba, L. M. Buravtseva, O. Churiukova, Yu. V. Horbatenko, New thermal conductivity mechanism in triclinic 4bromobenzophenone crystal, Chem. Phys. Lett. 647 (2016) 55-58.

[12] O. O. Romantsova, Yu. V. Horbatenko, A. I. Krivchikov O. A. Korolyuk, G. A. Vdovichenko, D. I. Zloba, and O. S. Pyshkin, Anomalous heat transfer in two polymorphs of 
para-bromobenzophenone, Fiz. Nizk. Temp. 43 (2017) 486-491 (Low Temp. Phys. 43 (2017) 395-399).

[13] A. Jeżowski, M. A. Strzhemechny, O. S. Pyshkin, A. I. Krivchikov, O. O. Romantsova, O. A. Korolyuk, Yu.V. Horbatenko, A. Filatova, in press.

[14] M. Hassaine and M. A. Ramos, A. I. Krivchikov, I. V. Sharapova, and O. A. Korolyuk, R. J. Jiménez-Riobóo, Low-temperature thermal and elastoacoustic properties of butanol glasses: Study of position isomerism effects around the boson peak, Phys. Rev. B 85 (2012) 104206.

[15] A. I. Krivchikov, A. N. Yushchenko, V. G. Manzhelii, O. A. Korolyuk, F. J. Bermejo, R. Fernandez-Perea, C. Cabrillo, and M. A. Gonzalez, Scattering of acoustic phonons in disordered matter: A quantitative evaluation of the effects of positional versus orientational disorder, Phys. Rev. B 74 (2006) 060201.

[16] S. Shenogin, A. Bodapati, P. Keblinski, and A. J. H. Mc-Gaughey, Predicting the thermal conductivity of inorganic and polymeric glasses: The role of anharmonicity, J. Appl. Phys. 105 (2009) 034906-034907.

[17] P. B. Allen and J. L. Feldman, Thermal conductivity of disordered harmonic solids, Phys. Rev. B 48 (1993) 12581-12588.

[18] D. Szewczyk, A. Jeżowski, G. A. Vdovichenko, A. I. Krivchikov, F. J. Bermejo J. Ll. Tamarit, L. C. Pardo, and J. W. Taylor, Glassy Dynamics versus Thermodynamics: The Case of 2-Adamantanone, J. Phys. Chem. B 119 (2015) 8468-8474.

[19] L. H. Thomas, J. M. Cole and C. C. Wilson, Orientational disorder in 4chloro-nitro-benzene, Acta Cryst. C 64 (2008) o296-0302.

[20] C. A. Meriles, S. C. Perez, and A. H. Brunetti, Order-disorder phase transition in pchloronitrobenzene studied by NQR and DTA, Phys. Rev. B 54 (1996) 7090-7093.

[21] C. A. Meriles, J. F. Schneider, Y. P. Mascarenhas and A. H. Brunetti, X-ray diffraction study of polycrystalline p-chloro-nitro-benzene, J. Appl. Cryst. 33 (2000) 71-81.

[22] Y. Tozuka, Y. Yamamura, K. Saito, and M. Sorai, Thermodynamic study of a phase transition between the ordered and disordered phases and orientational disorder in crystalline pchloronitrobenzene, J. Chem. Phys. 112 (2000) 2355-2360.

[23] K. Saito, H. Kobayashi, Y. Miyazaki, M. Sorai, Anomalous lattice heat capacity of orientationally glassy crystal of p-chloronitrobenzene at low temperatures, Solid State Communications 118 (2001) 611-614.

[24] R. Brand, P. Lunkenheimer, and A. Loidl, Relaxation dynamics in plastic crystals, J. Chem. Phys. 116 (2002) 10386-10401. 
[25] N. T. Correia, J. J. M. Ramos, H. P. Diogo, The orientational glass transition in pentachloronitrobenzene: a study by differential scanning calorimetry and thermally stimulated currents, J. Phys. and Chem. of Solids 63 (2002) 1717-1722.

[26] L. H. Thomas, T. R. Welberry, D. J. Goossens, A. P. Heerdegen, M. J. Gutmann, S. J. Teat, P. L. Lee, C. C. Wilson and J. M.Cole, Disorder in pentachloronitrobenzene, $\mathrm{C}_{6} \mathrm{Cl}_{5} \mathrm{NO}_{2}$ : a diffuse scattering study, Acta Cryst. B 63 (2007) 663-673.

[27] J. F. Gebbia, M. A. Ramos, D. Szewczyk, A. Jezowski, A. I. Krivchikov, Yu. V. Horbatenko, T. Guidi, F. J. Bermejo, and J. Ll. Tamarit, Glassy Anomalies in the LowTemperature Thermal Properties of a Minimally Disordered Crystalline Solid, Phys. Rev. Lett. 119 (2017) 215506.

[28] M. Romanini, M. Barrio, S. Capaccioli, R. Macovez, M. D. Ruiz-Martin, and J. Ll. Tamarit, Double Primary Relaxation in a Highly Anisotropic Orientational Glass-Former with LowDimensional Disorder, J. Phys. Chem. C 120 (2016) 10614-10621.

[29] K. Kishimoto, H. Suga, S. Seki, Calorimetric Study of the Glassy State. XIV. Calorimetric Study on Unusual Glass Transition Phenomena in $\mathrm{CFCl}_{2}-\mathrm{CFCl}_{2}, \mathrm{Bull}$. Chem. Soc. Jpn. 51, (1978) 1691-1696.

[30] M. Rovira-Esteva, N. A. Murugan, L. C. Pardo, S. Busch, J. Ll. Tamarit, Sz. Pothoczki, G. J. Cuello, and F. J. Bermejo, Interplay between intramolecular and intermolecular structures of 1,1,2,2-tetrachloro-1,2-difluoroethane, Phys. Rev. B 84 (2011) 064202.

[31] V. P. Kolesov, E. A. Kosarukina, D. Yu. Zhogin, M. E. Poloznikova, and Yu. Pentin, Heat capacities, phase transitions, and thermodynamic functions of 1,1,2,2-tetrafluoro-1,2dichloroethane and 1,1,2-trifluoro-1,2,2-trichloroethane, J. Chem. Thermodyn. 13 (1981) 115129.

[32] V. Kolesov, The order-disorder transitions in some organic crystals, Thermochim. Acta 266 (1995) 129-145.

[33] G. A. Vdovichenko, A. I. Krivchikov, O. A. Korolyuk, J. Ll. Tamarit, L. C. Pardo, M. Rovira-Esteva, F. J. Bermejo, M. Hassaine, and M. A. Ramos, Thermal properties of halogenethane glassy crystals: Effects of orientational disorder and the role of internal molecular degrees of freedom, J. Chem. Phys. 143 (2015) 084510.

[34] A. Vispa, A., Romanini, M., Ramos, M. A., Pardo, L. C., Bermejo, F. J., Hassaine, M., A. I. Krivchikov, J. W. Taylor, and J. Ll. Tamarit, Thermodynamic and Kinetic Fragility of Freon 113: The Most Fragile Plastic Crystal, Phys. Rev. Lett., 118 (2017) 105701.

[35] L. C. Pardo, P. Lunkenheimer, and A. Loidl, $\alpha$ and $\beta$ relaxation dynamics of a fragile plastic crystal, J. Chem. Phys. 124 (2006) 124911. 
[36] A. Jeżowski, J. Mucha and G. Pompe, Thermal conductivity of the amorphous alloy $\mathrm{Fe}_{40} \mathrm{Ni}_{40} \mathrm{P}_{14} \mathrm{~B}_{6}$ between 80 and 300 K, J. Phys. D: Appl. Phys. 20 (1987) 1500-1506.

[37] A. Jeżowski, B.A. Danilchenko, M. Boćkowski, I. Grzegory, S. Krukowski, T. Suski, T. Paszkiewicz, Thermal conductivity of GaN crystals in 4.2-300 K range, Solid State Commun. 128 (2003) 69-73.

[38] A. I. Krivchikov, B. Ya. Gorodilov, and O. A. Korolyuk, A Setup for Studying the LowTemperature Thermal Conductivity of Powder Samples, Instruments and Experimental Techniques 48.3 (2005) 417-421.

[39] A. I. Krivchikov, V. G. Manzhelii, O. A. Korolyuk, B. Ya. Gorodilov, and O. O. Romantsova, Thermal conductivity of tetrahydrofuran hydrate, Phys. Chem. Chem. Phys. 7.5 (2005) 728-730.

[40] O.A. Korolyuk, A.I. Krivchikov, G.A. Vdovichenko, O.O. Romantsova, and Yu.V. Horbatenko, Thermal conductivity of solid thiophene in an incommensurate orientational state, Low Temp. Phys. 42.1 (2016) 68-73.

[41] I. V. Sharapova, A. I. Krivchikov, and O. A. Korolyuk, A. Jeżowski, M. Rovira-Esteva, J. L1. Tamarit, L. C. Pardo, and M. D. Ruiz-Martin, F. J. Bermejo, Disorder effects on heat transport properties of orientationally disordered crystals, Phys. Rev. B 81 (2010) 094205.

[42] X. Gao, Y. Nagasaka, and A. Nagashima, Thermal Conductivity of HFC-32, HFC-125, and HFC-134a in the Solid Phase, International Journal of Thermophysics 19 (1998) 415-425.

[43] R. C. Yu, N. Tea, M. B. Salamon, D. Lorents, and R. Malhotra, Thermal conductivity of single crystal $\mathrm{C}_{60}$, Phys. Rev. Lett. 68.13 (1992) 2050-2053.

[44] W. Lv and A. Henry, Direct calculation of modal contributions to thermal conductivity via Green-Kubo modal analysis, New J. Phys. 18 (2016) 013028.

[45] W. Lv, A Correlation Based Theory for Phonon Transport, PhD Dissertation, Georgia Inst. of Technology, 2017.

[46] M. Romanini, Ph. Negrier, J. Ll. Tamarit, S. Capaccioli, M. Barrio, L. C. Pardo, and D. Mondieig, Emergence of glassy-like dynamics in an orientationally ordered phase, Phys. Rev. B 85 (2012) 134201.

[47] J. H. S. Green and D. J. Harrison, Vibrational spectra of benzene derivatives-X: Monosubstituted nitrobenzenes, Spectrochimica Acta Part A: Molecular Spectroscopy, 26(9) (1970) 1925-1937.

[48] J. K. Kruger, J. Schreiber, R. Jimenez, K. P. Bohn, F. Smutny, M. Kubat, J. Petzelt, J. Hrabovska-Bradshaw, S. Kamba, and J. F. Legrand, Unconventional orientational glass transitions in symmetrical difluorotetrachloroethane, J. Phys.: Condens. Matter 6 (1994) 69476964. 
[49] Karine Le Bris, Kimberly Strong, Stella M.L. Melo, Jason C. Ng, Structure and conformational analysis of $\mathrm{CFC}-113$ by density functional theory calculations and FTIR spectroscopy, Journal of Molecular Spectroscopy 243 (2007) 142-147.

[50] B. Ben Hassine, Ph. Negrier, M. Romanini, M. Barrio, R. Macovez, A. Kallel, D. Mondieig and J.L1.Tamarit, Structure and reorientational dynamics of 1-F-adamantane, Phys. Chem. Chem. Phys. 18 (16) (2016) 10924-10930.

[51] D. Szewczyk, A. Jeżowski, A. Krivchikov, J. F. Gebbia, T. Guidi and J. Ll. Tamarit, to be submitted.

[52] W. Lv and A. Henry, Non-negligible Contributions to Thermal Conductivity From Localized Modes in Amorphous Silicon Dioxide, Sci. Reports 6 (2016) 35720-1- 35720-6.

[53] E. E. Anders, I. V. Volchok, A. I. Zvyagin, V. B. Kokshenev, and S. V. Startsev, Thermal properties of cesium-rare earth molybdates, Fiz. Nizk. Temp. 11 (1985) 769-774 (in russian).

[54] D. Stanić, P. Popčević, I. Smiljanić, A. Bilušić, I. Batistić, J. Ivkov, and A. Smontara, Thermal conductivity of Taylor phase $\mathrm{T}-\mathrm{Al}_{73} \mathrm{Mn}_{27}$ complex metallic alloy, Journal of Physics: Conference Series 226(1) (2010) 012034. IOP Publishing.

[55] I. Smiljanić, A. Smontara, A. Bilušić, N. Barišić, D. Stanić, J. Lukatela, and B. Grushko, Thermal and electrical conductivities in Al-based complex metallic alloys, Philosophical Magazine 88(13-15) (2008) 2155-2162.

[56] D. Stanić, P. Popčević, I. Smiljanić, Ž. Bihar, A. Bilušić, I. Batistić, and M. Feuerbacher, Thermal Conductivity of Taylor Phase $\mathrm{Al}_{3}(\mathrm{Mn}, \mathrm{Pd})$ Complex Metallic Alloys, Croatica chemica acta, 83(1) (2010) 81-86.

[57] D. Stanić, Charge transport and heat of complex metal compounds $\mathrm{Al}_{73} \mathrm{Mn}_{27}(\mathrm{Pd}, \mathrm{Fe}) \mathrm{x}$, Diss. Prirodoslovno-matematički fakultet, Sveučilište u Zagrebu, (2009).

[58] J. Dolinšek, S. Vrtnik, M. Klanjšek, Z. Jagličić, A. Smontara, I. Smiljanić, and C. V. Landauro, Intrinsic electrical, magnetic, and thermal properties of single-crystalline $\mathrm{Al}_{64} \mathrm{Cu}_{23} \mathrm{Fe}_{13}$ icosahedral quasicrystal: Experiment and modeling. Phys. Rev. B, 76(5) (2007) 054201. 